\title{
Comparative Braking Performance Evaluation of a Commercial and Non-asbestos, Cu-free, Carbonized Friction Composites
}

\author{
Zhenyu WANG ${ }^{1,2}$, Jie WANG ${ }^{1 *}$, Fenghong $\mathrm{CAO}^{3}$, Yunhai $\mathrm{MA}^{4}$ \\ ${ }^{1}$ School of Mechanical Engineering, Sichuan University, Chengdu 610065, P. R. China \\ ${ }^{2}$ The Engineering \& Technical College of Chengdu University of Technology, Leshan 614000 P. R. China \\ ${ }^{3}$ School of Physics and Electronic Engineering, Leshan Normal University, Leshan 614000, P. R. China \\ ${ }^{4}$ College of Biological and Agricultural Engineering, Jilin University, Changchun 130022, P. R. China \\ crossref http://dx.doi.org/10.5755/j02.ms.23525
}

Received 04 June 2019; accepted 14 October 2019

\begin{abstract}
Carbonization treatment contributes to improvement of tribological properties of friction composites. Pure Non-asbestos organic (NAO) friction raw materials were selected, friction composite specimens had been made using a new mixing process and carbonization treatment. Two types of specimens had been prepared to evaluate their performance, one was carbonized a pure non-asbestos organic friction composite specimen and the other was an original brake metal linings of a certain brand of vehicles. Two friction composites were evaluated by brake inertia dynamometer. Their performances were assessed according to the procedure in a European Union Automobile Standards (AK Master). Microscopic photographs of worn surfaces were obtained by scanning electron microscopy to characterize their tribological behavior and wear mechanism. The results showed that pure NAO friction composites had more suitable frictional properties, fade and recovery behavior than the copper-containing metal brake pad, but wear resistance was slightly lower. Carbonation promoted the formation of microporous structure in friction composites, which was helpful to reduce noise and vibration during work.

Keywords: NAO friction materials, friction and wear, brake dynamometer, comparative test, tribology.
\end{abstract}

\section{INTRODUCTION}

Among brakes, clutches and driving devices of many vehicles, friction composites make up important part [1]. The reliability and stability of the executive components are directly linked with friction composites. Hence, suitable friction coefficients and better wear resistance under various temperatures and complex conditions must be presented [2]. The friction composites should be noisefree and vibration-free in working condition. Moreover, the friction material should not be harmful to human and environment [3]. So they are usually made up of various ingredients, such as resin binder, fibers, abrasive fillers, lubricating or antifriction agent, and quality modifiers $[4,5]$. The influence of each category on the performance parameters of friction material have been extensively discussed and reported in the literature [6-9].

Numerous friction and wear testing mean for these friction composites (FMs) are quite popular globally, such as brake-dynamometer tester [10], Krauss tester [11], FAST tester [12], Chase tester [13] etc. Among these, Chase and FAST are commonly used for process quality testing [14]. With the emergence of high speed heavy load vehicle vehicles, the working conditions of brake lings and pads became more complicated. Therefore, it is quite essential to conduct full-scale inertia dynamometer testing so as to match these requirements, because this device can meet various test requirements under different working conditions [15-19].

\footnotetext{
* Corresponding author. Tel.: +86-2885405302; fax: +86-2885460940.

E-mail address:wangjie@scu.edu.cn (J. Wang)
}

Copper had been certified to be one of the essential fillers in friction composites because of its excellent properties [20-22]. However, environmental protection had forced a significant decline in its utilization rate. According to reports, brake wear debris that is being released onto the streets or into the air ends up in the waterways. The copper in the brake pad debris can be toxic to aquatic organisms. These bases of the food chain affect the health of entire ecosystems. The United States had strictly controlled the content of copper in brake pads at less than $0.5 \%$ [23]. Aranganathan N. et al. [24] studied the tribological behavior of copper-free brake-friction material. Rongping Yun. et al. [25] revealed that Ecofriendly brake friction materials were formulated without copper, lead, tin, antimony trisulfide, and whisker materials, to minimize their potential negative environmental impacts. Ilanko A K. et al. [26] reported that asbestos-free eco-friendly composites for automobile brake materials, based on biodegradable and non-toxic properties, and availability from natural sources. Lee $\mathrm{P}$ W. et al. [23] developed friction and wear performance of $\mathrm{Cu}$ free and $\mathrm{Sb}$-free environmentally friendly automotive brake friction materials. Idris U D et al. [27] evaluated the tribological characteristics of eco-friendly asbestos free brake-pad containing banana peels. The result of this research indicates that banana peel particles can be effectively used as a replacement for asbestos in brake pad manufacture. In addition, natural fibers, including pineapple leaf/coir Fiber, hemp fiber, banana fiber, jute fiber, etc., which are environmentally friendly, low cost, biodegradable, etc., were used in the preparation of environmentally friendly friction composites [28-32]. 
In this study, environmentally friendly and economical fillers were added, new mixing and heat treatment processes were used. Two samples had been prepared to evaluate their performance, one was a pure non-asbestos organic friction specimen and the other was an original brake linings of a certain brand of vehicles, which contains copper powder. Their friction and wear properties had been investigated on a full-scale braking dynamometer. These morphologies of wear surface were obtained using SEM.

\section{MATERIALS AND METHODOLOGY}

\subsection{Material selection}

The raw ingredients of friction composites and mass ratio are shown in Table 1 . The resin was used as polymer adhesive; organic fiber, kevlar and acrylic fiber were used as reinforcing fiber; powders such as water slag, purple clay, shale, and silica were used as fillers. Water slag was an industrial waste, purple clay, shale, and silica were functional fillers with ceramic properties.

Table 1. The raw ingredients of friction composites and mass ratio (wt \%)

\begin{tabular}{|l|l|c|}
\hline Raw materials & \multicolumn{1}{|c|}{ Manufacturer } & $\begin{array}{c}\text { Mass } \\
\text { fraction }\end{array}$ \\
\hline Phenolic resin & $\begin{array}{l}\text { Jinan SQHWS Chemical Industry } \\
\text { Co. Ltd. }\end{array}$ & 10 \\
\hline Organic fiber & Wujin friction material Co. Ltd. & 3 \\
\hline Kevlar & Dupont China Holding Co.LTd. & 2 \\
\hline Acrylic fiber & Dupont China Holding Co.LTd. & 3 \\
\hline $\begin{array}{l}\text { Brown } \\
\text { corundum }\end{array}$ & Zibo Lihai Trade Co. Ltd. & 1 \\
\hline Water slag & JiuTong friction materialCo.Ltd & 13 \\
\hline Purple sand & JiuTong friction materialCo.Ltd & 14 \\
\hline Shale & JiuTong friction materialCo.Ltd & 12 \\
\hline Rubber powder & Sang Hing Hong Chemical Ltd. & 7 \\
\hline Silica & JiuTong friction materialCo.Ltd & 13 \\
\hline $\begin{array}{l}\text { Vermiculite } \\
\text { powder }\end{array}$ & $\begin{array}{l}\text { Hebei Jinjian Mining Industry Co. } \\
\text { Ltd. }\end{array}$ & 10 \\
\hline $\begin{array}{l}\text { Friction } \\
\text { powder }\end{array}$ & Haiyan Huaqiang Resin Co. Ltd. & 5 \\
\hline Husk powder & JiuTong friction materialCo.Ltd & 7 \\
\hline
\end{tabular}

\subsection{Preparation of the specimens}

The mixer with model JF805R was used as a mixing device. All materials, including resins, fibers, fillers, etc., were mixed for 10 minutes. In the meantime, a small amount of water was sprayed through the top water inlet during the mixing process to prevent dust from appearing. Because no metal was contained in the mixing materials, these materials were dried using a microwave heating method. Mixed wet materials were placed on the conveyor belt of the equipment, using microwave heating for about 8 min, as shown in Fig. 1. Wet mixing and microwave heating methods were used in the mixing process, which was a new approach completely. This approach fundamentally solved the dust pollution problem caused by the traditional dry technology in the mixing process.

A hydraulic power machine with model JFY61 was used as a molding equipment. After drying, the mixture was molded under pressure of $40 \mathrm{MPa}$. The molding time was set at 30 minutes, and the temperature was controlled at $165^{\circ} \mathrm{C}$. Three breathings were allowed in the hotpressing process to release volatiles that evolved from the chemical reaction of the phenolic resin.

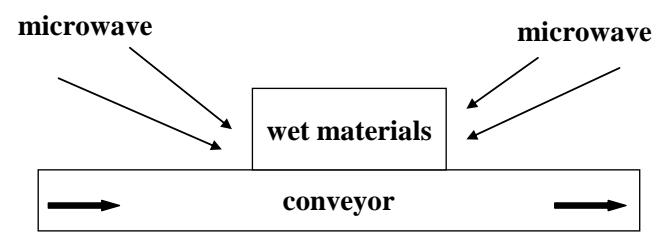

Fig. 1. Schematic of microwave heating

Heat treatment was followed to remove the residual stress generated during hot pressing [33]. The heat treatment process is illustrated in Fig. 2, which was mainly divided into three phases. The temperature at each phase was $140{ }^{\circ} \mathrm{C}, 160{ }^{\circ} \mathrm{C}$ and $180{ }^{\circ} \mathrm{C}$, and the holding time was 1 hour, 3 hours and 6 hours continually. Finally, the temperature would be close to $20^{\circ} \mathrm{C}$ [34]. Two types of samples were subjected to the same hot pressing process and heat treatment process.

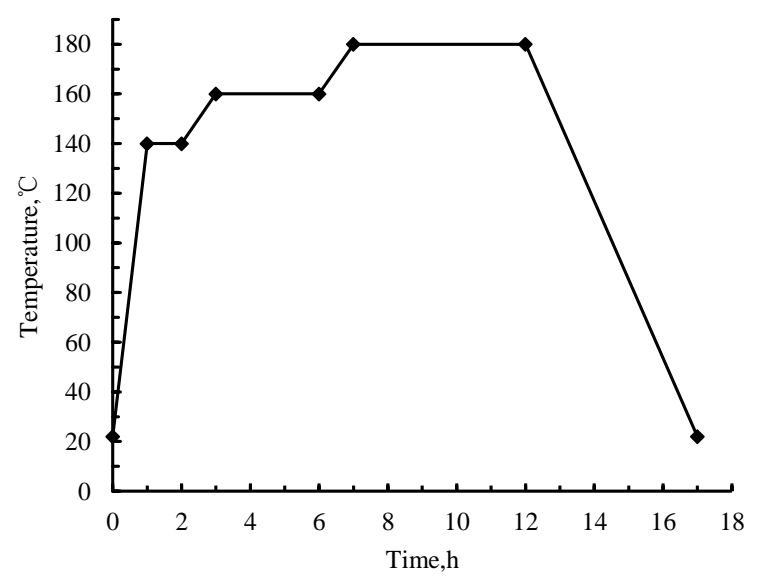

Fig. 2. Heating process for friction composites

Carbonization could be a more effective approach in enhancing the high temperature tribological performance of phenolic resin-based friction materials [35]. The developed friction composites were pure NAO friction materials without adding any metal. To stabilize the friction coefficient of friction composites at high temperature, friction specimens were carbonized in a carbonization furnace at $400{ }^{\circ} \mathrm{C}$ for $5 \mathrm{~min}$. To reduce the temperature of the backing plate and ensure its shear strength resistance, the circulating water flowed under the carbonization furnace. The schematic of carbonization treatment is displayed in Fig. 3. After the carbonization treatment, resins, several fibers and organic powders were carbonized and volatilized, and the microporous structure appeared on the surface of the sample, forming stable carbonization layer.

The developed friction material samples and the original brake linings of a certain brand of vehicles were prepared for the comparative tests. The original brake linings of a certain brand of vehicles were metal friction materials, which contained a certain amount of copper powder and iron powder. The developed friction material 
samples were named as DF, and the original brake linings were named as $\mathrm{OF}$.

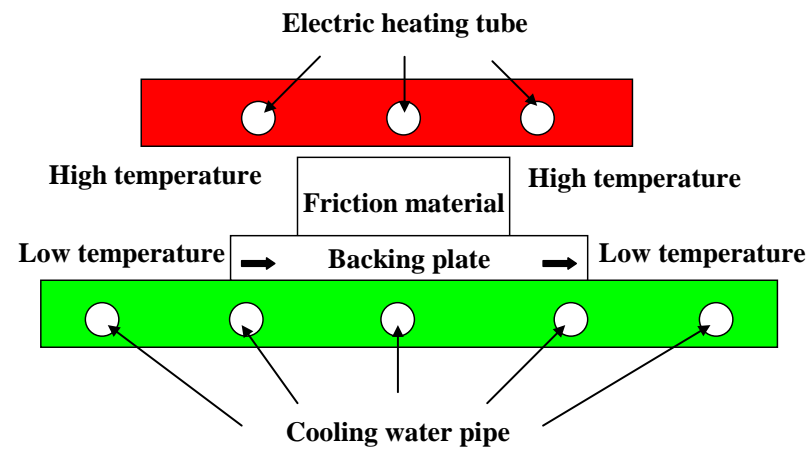

Fig. 3. Schematic of carbonization treatment

\subsection{Tester and schedule}

These two samples were evaluated on the dynamometer supplied by Jilin Wanda Mechanical Co. Ltd., Changchun, China. The structure diagram of the dynamometer is displayed in Fig. 4 a, and Fig. 4 b shows a photo of the brake measurement section.

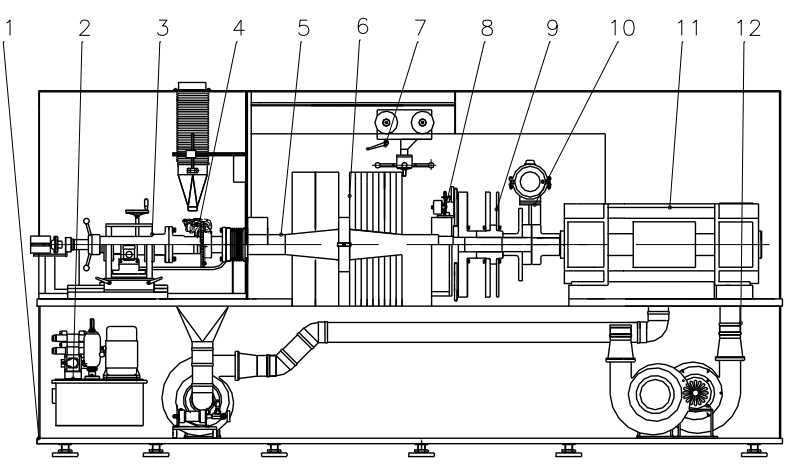

a

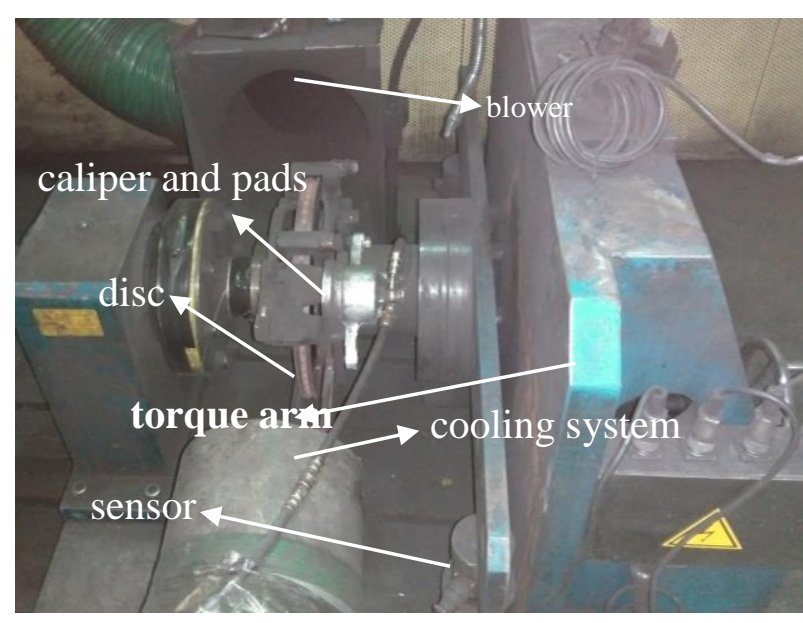

b

Fig. 4. a - structure diagram of brake dynamometer: (1) dyno bed, (2) hydraulic system, (3) sliding table, (4) braking assembly, (5) shaft, (6) equidifferent flying wheels assemblies, (7) flying wheels moving device, (8) Emergency brakes, (9) geometrical flying wheels, (10) emergency brakes, (11) motor, (12) cooling system; bclose view of braking end

This dynamometer can perform various schedules such as AK Master, JASO, VW-PV3212, SAE J2681 etc. The
European Union Automobile Standards (AK Master) schedule was carried out in this test. The Automobile Standards (AK Master) describes the friction value behavior of a friction material with regard to the influences of pressure, temperature and speed. To take account of the different cooling behavior and the fading series of the different test standards, the temperature was strictly controlled by procedure. The AK Master test procedure includes the following test items: Characteristic value $\mu$ green, Bedding, Characteristic value, Speed/Pressure line, Characteristic value, Cold application, Motorway applications, Characteristic/recovery, Fade 1, Pressure line, Incremental temperature, Fade 2 etc. Total of 276 brake applications have been made.

\section{RESULTS AND DISCUSSION}

Fig. 5 indicates the sensitivity of $\mu$ for increasing pressure and varying temperature under selected speeds for samples. Fig. 6 is fade characteristics. Fig. 7 collects the data on recovery characteristics of samples.

\subsection{Friction performance}

\subsubsection{Pressure-speed sensitivity}

At the lowest speed (40 kmph), the $\mu$ of DF was in the range of $0.33-0.53$. It increased with pressure till 50 bar, then tended to stabilize and slightly decrease. The temperature of DF was in the range of $112-120^{\circ} \mathrm{C}$. When the pressure was $20 \mathrm{bar}$, the temperature reached the highest $120^{\circ} \mathrm{C}$. The $\mu$ of $\mathrm{OF}$ was in the range of $0.39-0.50$. Under the pressure of $30 \mathrm{bar}$, it increased with the pressure up to $30 \mathrm{bar}$, and then tended to decrease slowly. The temperature of $\mathrm{OF}$ was in the range of $106-112^{\circ} \mathrm{C}$. When the pressure was $60 \mathrm{bar}$, the temperature reached the highest $112^{\circ} \mathrm{C}$.

At lower speed $(80 \mathrm{kmph})$, the $\mu$ of DF was between 0.29 and 0.49 , while the $\mu$ of OF was between 0.29 and 0.48 . The $\mu$ of the two FMs had the same minimum value at the pressure 10 bar. The temperature of the two FMs increased and then decreased with the increasing of pressure. There were two fluctuations in the process, the temperature difference of DF was $92{ }^{\circ} \mathrm{C}$, while $\mathrm{OF}$ was only $31{ }^{\circ} \mathrm{C}$.

At moderate speed $(120 \mathrm{kmph})$, the minimum and maximum friction coefficients were 0.27 and 0.46 , respectively. The difference in $\mu$ behavior was negligible. The decline in slope (pressure-fade) started quite early around 30-40 bar pressure. The $\mu$ of DF fluctuated relatively less than the $\mu$ of $\mathrm{OF}$. The temperature fluctuation of the two FMs had the same trend. The lowest temperature of DF was $154{ }^{\circ} \mathrm{C}$, while OF was only $114^{\circ} \mathrm{C}$.

At higher speed $(160 \mathrm{kmph})$, the friction coefficient curves of the two FMs were quite perfect, and the $\mu$ pressure curve approximated a straight line after 40 bar pressure. It indicated the low sensitivity of $\mu$ to pressure. The temperature of the two FMs was in the range of $141-194^{\circ} \mathrm{C}$.

At the highest speed $(180 \mathrm{kmph})$, the $\mu$ of DF varied from 0.26 to 0.45 , while the $\mu$ of $\mathrm{OF}$ varied from 0.25 to 0.41 . At each braking pressure, the $\mu$ of DF was higher than the $\mu$ of OF. 


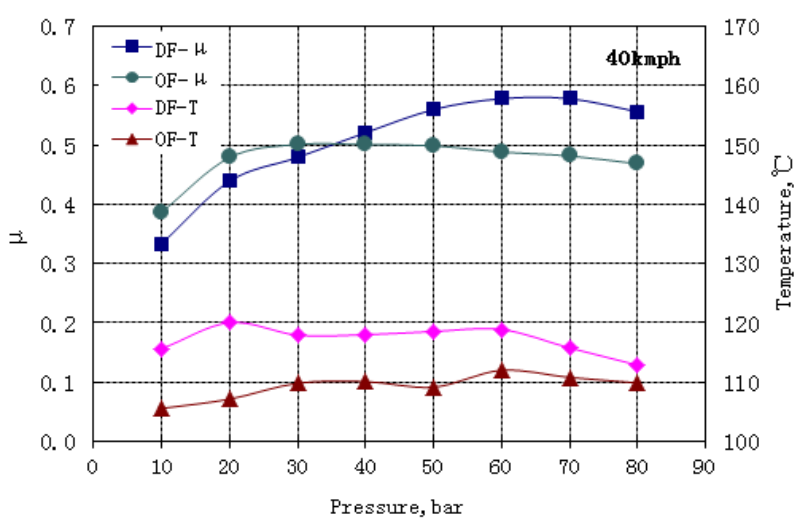

a

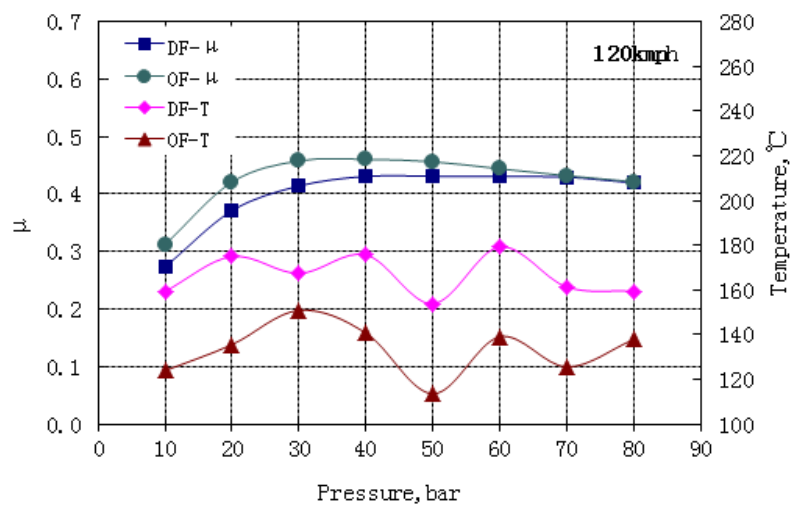

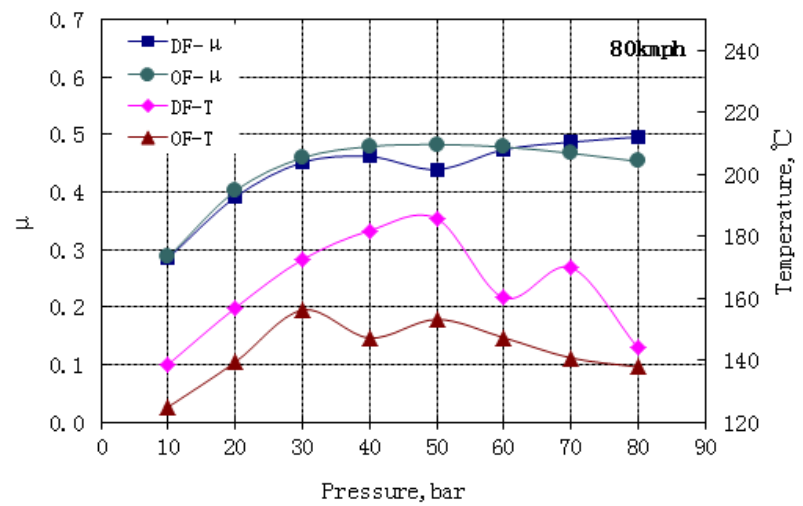

b

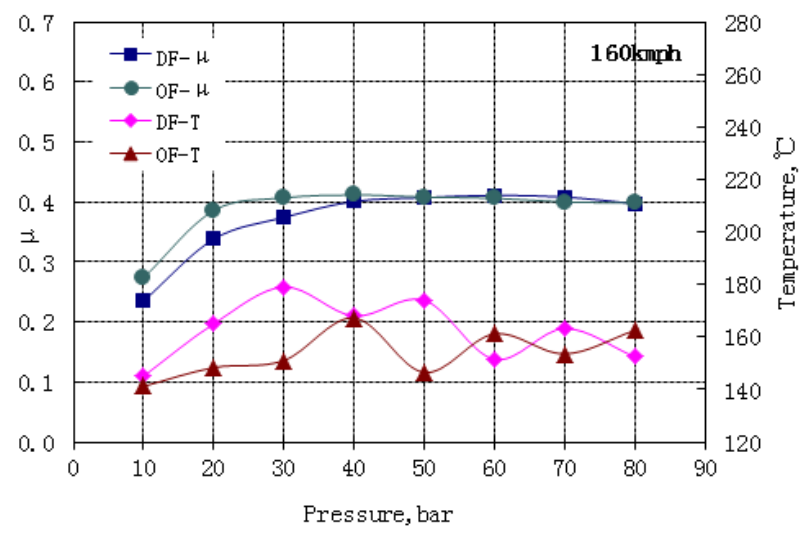

d

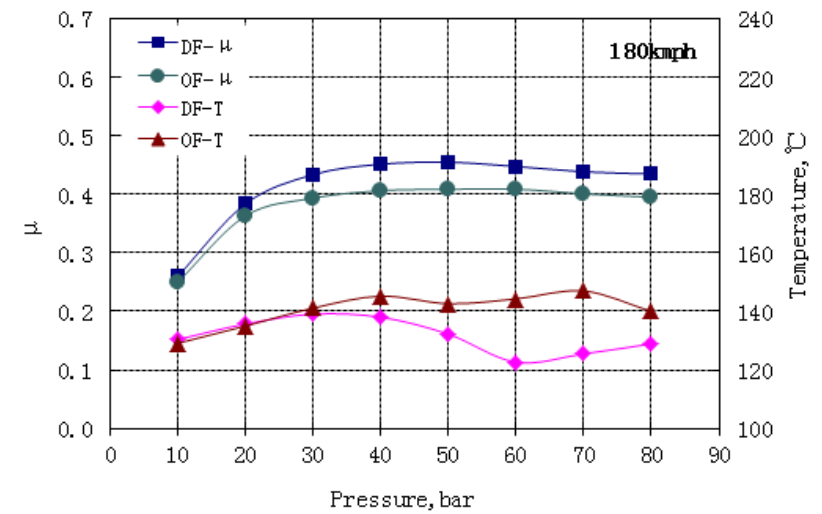

Fig. 5. Variation in $\mu$ with increase in Pressure at five given speeds (kmph): $a-40 ; b-80 ; c-120 ; d-160 ; e-180$

After 40 bar pressure, their difference in $\mu$ was nearly equal, and the value was about 0.04. The temperature variation curve of DF was below OF. Their temperature's range was equal about $17^{\circ} \mathrm{C}$.

The copper-containing friction composite OF could form a uniform friction film on the mating surface, and its pressure-speed sensitivity was smaller. The coefficient of the carbonized organic NAO friction composite DF was relatively stable at a given speed.

\subsubsection{Temperature sensitivity}

As shown in Fig. 6, fade I indicated the first fade cycle on the fresh disc, and fade II showed the second fade cycle subsequent to fade I.

The friction coefficient and temperature variation curves were plotted through 15 times of braking. The fading tendency observed in the second cycle was lower than that in the first cycle. In fade I cycle, the $\mu$ for DF changed from 0.54 to 0.34 , while the $\mu$ for OF varied from 0.47 to 0.36 .

As can be seen from Fig. 7, recovery I exhibited the first recovery cycle, and recovery II demonstrated the second recovery cycle subsequent to fade I, recovery I and fade II cycles. After 18 times of braking, the $\mu$ and temperature values were recorded every three times. As can be observed clearly, the $\mu$ of recovery I was usually lower than recovery II.

M. Kumar and J. Bijwe [21] reported that the thermal conductivity of friction composites increased with the addition of copper, the heat was rapidly extracted from the sliding surface, the amount of degradation of the polymer was reduced. The quality of transfer film on the friction 
interface was greatly improved and the anti-fade property was enhanced.
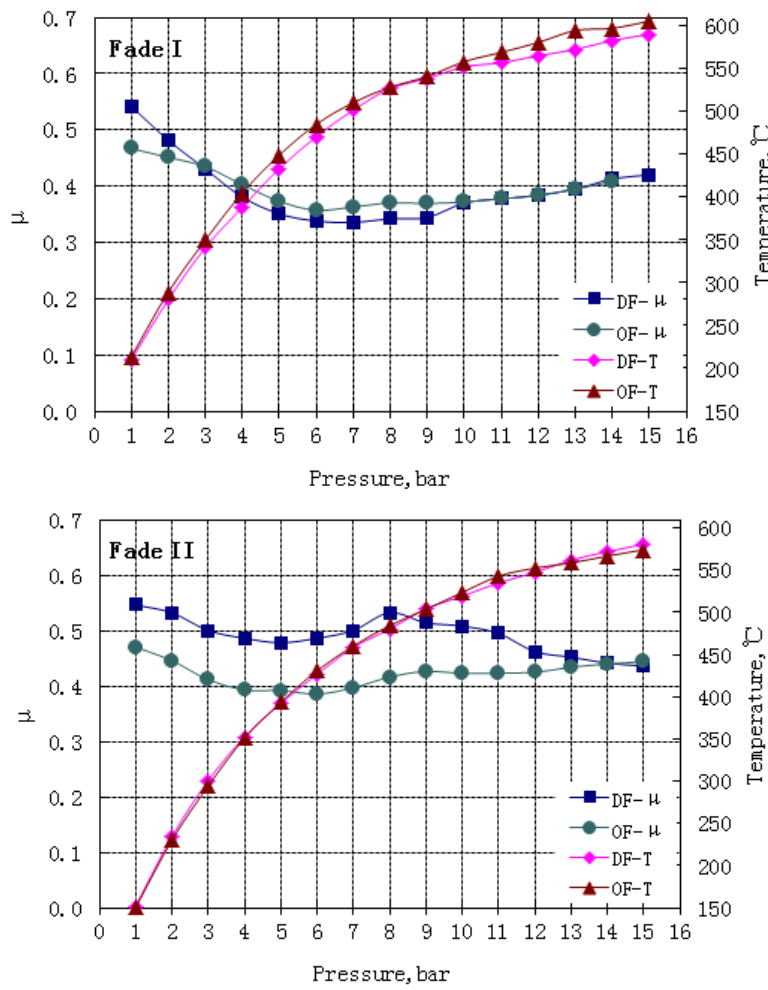

Fig. 6. Decrease in $\mu$ with increase in temperature (fade) of FMs
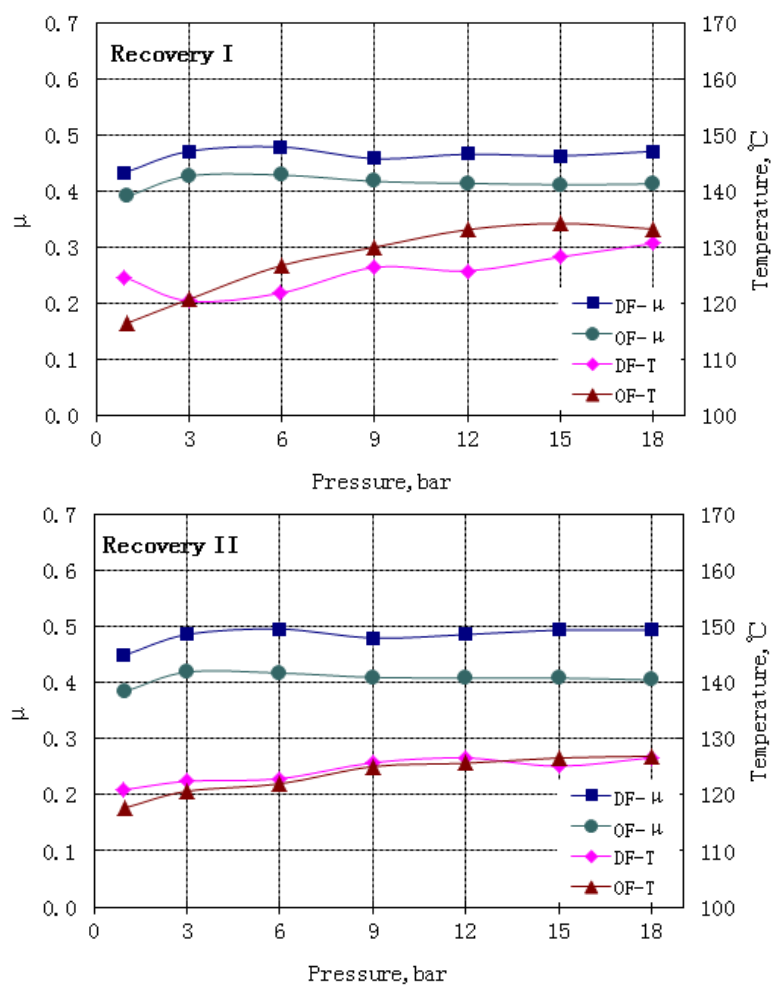

Fig. 7. Recovery of $\mu$ after fade cycles for selected FMs

In fade I, with the increase of temperature, the friction coefficient curve decreased and then increased, and the temperature and friction coefficient of the two friction composites were very similar. In decay fade II, the $\mu$ of DF was obviously higher than that of OF. In recovery cycle I and recovery II, it was obviously observed that the friction curves of DF were on the county of OF friction, and showed good recovery performance. In general, the heat fade resistance performance of DF was superior to that of $\mathrm{OF}$, which could be due to the fact that carbonization promoted the decomposition of the polymer in the friction composite and improved the tribological properties of high temperature. This was consistent with the previous research results [27].

\subsection{Wear performance}

In this study, three parallel tests were executed to reduce the data scattering. As shown in Fig. 8, Wear behavior of the two composites was measured by weight loss method. The OF indicated higher wear resistance and the average weight loss was $7.301 \mathrm{~g}$. The average weight loss of DF was $9.449 \mathrm{~g}$, indicating its low wear resistance. The total weight and thickness of the sample DF before weight loss were $345.626 \mathrm{~g}$ and $18.438 \mathrm{~mm}$, respectively. The maximum thickness loss given in the AK master schedule was $0.51 \mathrm{~mm}$, which was converted into a percentage of $27.6 \%$. The thickness loss of the DF sample was $0.496 \mathrm{~mm}$, which met the requirements. The weight loss percentage of sample DF was $27.3 \%$, which was considered to be in an acceptable range.

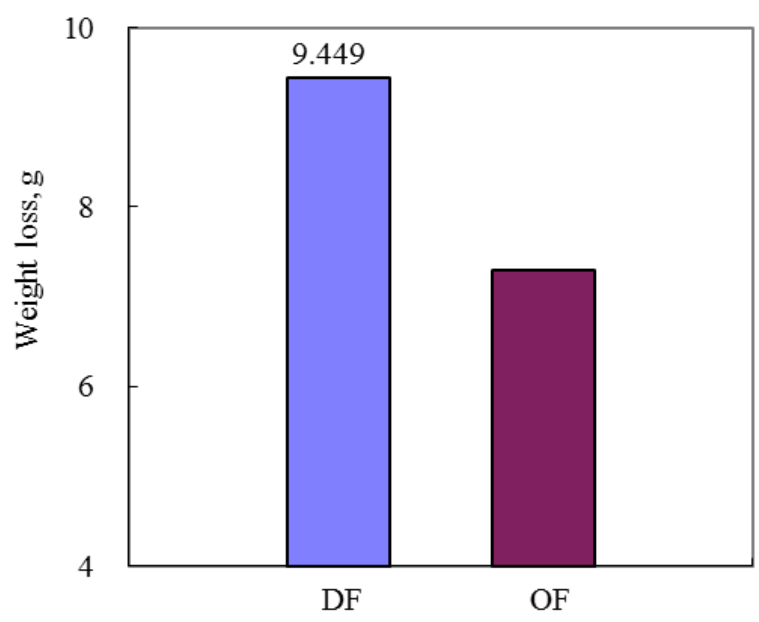

Fig. 8. Wear behavior of the two composites

\subsection{Microscopic wear surface analysis}

The microscopic surface morphology of friction composites before and after the test could directly reflect its tribological properties. The microstructure of friction specimen surface observed by SEM was helpful to explain results of friction and wear properties, and its wear mechanism could be further analyzed. The SEM micrographs of the composite DF before the friction tests are shown in Fig. 9. The typical worn morphologies of friction specimens are illustrated in Fig. $10 \mathrm{a}-\mathrm{d}$.

As observed in Fig. 9, resins, several kinds of fibers and organic powders were carbonized and volatilized, numerous micropores appeared on the surface of the sample. In this process, some ceramic fillers (such as purple clay, shale, and silica) had been sintered, forming a large number of carbonized sintered bodies with irregular shapes.

As can be seen from Fig. 10 a, non-uniform and noncontinuous surface. During the test, the brake pads slid 
against the friction disc. Some abrasive particles separated from the matrix and abrasive wear occurs.

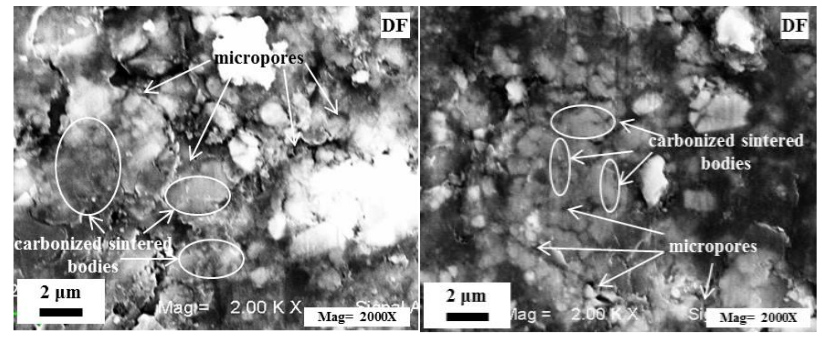

Fig. 9. SEM micrographs of composite DF before the friction tests

The lower wear resistance was closely related to the very severely damaged surface of friction composites. The worn surface of the friction composite OF (Fig. $10 \mathrm{~b}$ ) was observed to have a quite smooth topography, some amounts of secondary plateaus appeared. Uniform layers covered almost all other ingredients. Appreciable damage such as adhesive pit and microcracks on the surface could be exposed, so the main wear types were adhesive wear and fatigue wear. Overall-better wear resistance was perfectly associated with slightly damaged surfaces.

From Fig. $10 \mathrm{c}$, severe damage and cracks were observed on the surface, indicating a significant increase in wear of the composites. In addition, many fibers were pulled out and the worn surface was severely damaged (Fig. $10 \mathrm{~d}$ ). The fibers broke away from the substrate for the interfacial adhesion between fibers and substrate was weak at high temperature, which could then eventually lead to grooves. Some hard particles, which acted as abrasive of third body, embedded the soft worn surface and led to some parallel shallow grooves. The grooves existing on the friction surface could absorb the braking noise in certain degree. Therefore, the main wear mechanism of the friction composite DF was abrasive wear.

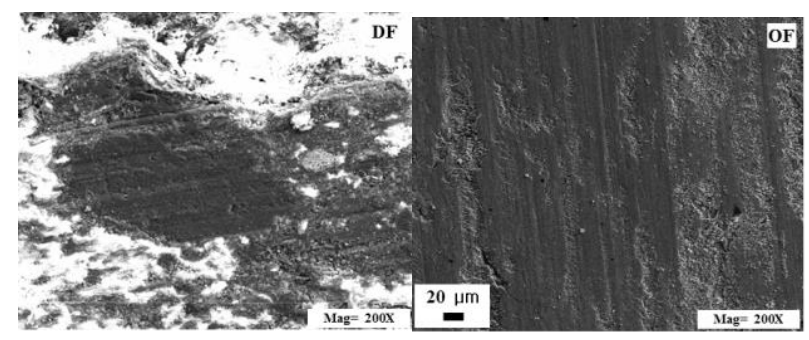

a

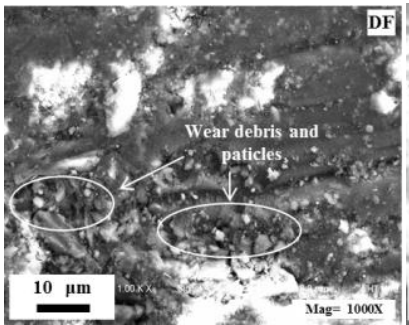

$\mathrm{b}$

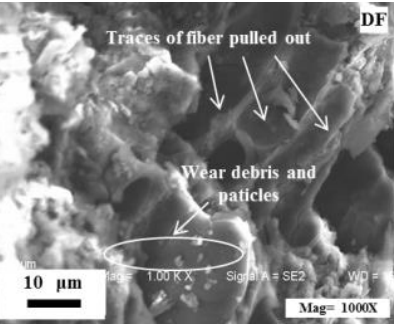

Fig. 10. SEM micrographs of samples after the friction tests

\section{CONCLUSIONS}

The composite DF was pure NAO friction materials that did not add any metal, while OF was a metal friction material, which contained a certain amount of copper powder and iron powder. Based on the test of the inertia dynamometer following conclusions were drawn.

1. Compared with OF, the composite DF had suitable friction and wear performance by carbonization treatment. Due to the addition of industrial waste, the composite DF also had good environmental friendliness and economy.

2. The copper-containing friction composite OF could form a uniform friction film on the mating surface, and its pressure-speed sensitivity was smaller. The coefficient of the carbonized organic NAO friction composite DF was relatively stable at a given speed.

3. The heat fade resistance performance of $\mathrm{OF}$ was superior to that of DF in fade I . The friction coefficient of DF in fade II was significantly higher than OF, which could be due to the fact that the treatment of using carbonization promoted the decomposition of the polymer in the friction composite and improved the tribological properties of high temperature.

4. The OF showed higher wear resistance and the DF exhibited lower wear resistance, but they were still within an acceptable range.

\section{Acknowledgments}

The work was supported by National Natural Science Foundation of China (Grant no.51075177), Leshan Science and Technology Development Plan Item (Grant no. 20ZDYJ0135), and School Youth Science Fund Project (Grant no. C122019020). Authors thank for the help provided by JiuTong friction material Co. Ltd to carry out the project.

\section{REFERENCES}

1. Ji, Z., Jin, H., Luo, W., Cheng, F., Hou, S. The Effect of Crystallinity of Potassium Titanate Whisker on the Tribological Behavior of NAO Friction Materials Tribology International 107 2017: pp. 213-220. https://doi.org/10.1016/j.triboint.2016.11.022

2. Kuroe, M., Tsunoda, T., Kawano, Y., Takahashi, A. Application of Lignin-Modified Phenolic Resins to Brake Friction Material Journal of Applied Polymer Science 129 (1) 2013: pp. 310-315. https://doi.org/10.1002/app.38703

3. Kim, Y.C., Cho, M.H., Kim, S.J., Jang, H. The Effect of Phenolic Resin, Potassium Titanate, and CNSL on the Tribological Properties of Brake Friction Materials Wear 264 (3-4) 2008: pp. 204-210. https://doi.org/10.1016/j.wear.2007.03.004

4. Vlastimil, M., $\quad$ Lu, Y., Jiao, L., $\quad$ Huang, L., Martynková, G.S., Tomáš ek, V. Effects of Silicon Carbide Particle Sizes on Friction-Wear Properties of Friction Composites Designed for Car Brake Lining Applications Tribology International 43 (1) 2009: pp. 144-151. https://doi.org/10.1016/j.triboint.2009.05.007

5. Tomášek, V., Kratošová, G., Yun, R., Fan, Y., Lu, Y. Effects of Alumina in Nonmetallic Brake Friction Materials on Friction Performance Journal of Materials Science 44 (1) 2009: pp. 266-273. https://doi.org/10.1007/s10853-008-3041-z 
6. Fei, J., Wang, H.K., Huang, J.F., Zeng, X.R., Luo, W. Effects of Carbon Fiber Length on The Tribological Properties of Paper-Based Friction Materials Tribology International 72 (4) 2014: pp. 179-186.

https://doi.org/10.1016/j.triboint.2013.12.017

7. Su, F.H., Zhang, Z.Z., Wang, K., Liu, W.M. Friction and

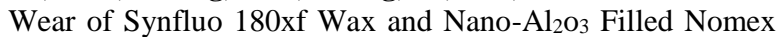
Fabric Composites Materials Science \& Engineering A (Structural Materials: Properties, Microstructure and Proccessing) $430(1-2)$ 2006: pp. 307-313. https://doi.org/10.1016/j.msea.2006.05.060

8. Mantia, F.P.L., Morreale, M. Green Composites: A Brief Review Composites Part a Applied Science \& Manufacturing 42 (6) 2011: pp. 0-588. https://doi.org/10.1016/j.compositesa.2011.01.017

9. Zhang, X., Li, K.Z., Li, H.J., Fu, Y.W., Fei, J. Tribological and Mechanical Properties of Glass Fiber Reinforced PaperBased Composite Friction Material Tribology International 69 2014: pp. $156-167$.

https://doi.org/10.1016/j.triboint.2013.08.003

10. Bian, G., Wu, H. Friction Surface Structure of a Cf/C-Sic Composite Brake Disc after Bedding Testing on a Full-Scale Dynamometer Tribology International 2016: pp. 85 -95. https://doi.org/10.1016/j.triboint.2016.03.010

11. Hwang, H.J., Jung, S.L., Cho, K.H., Kim, Y.J., Jang, H. Tribological Performance of Brake Friction Materials Containing Carbon Nanotubes Wear $268(3-4)$ 2010: pp. 519-525.

https://doi.org/10.1016/j.wear.2009.09.003

12. Kumar, M., Bijwe, J. NAO Friction Materials with Various Metal Powders: Tribological Evaluation on Full-Scale Inertia Dynamometer Wear 269 (11) 2010: pp. 826-837. https://doi.org/10.1016/j.wear.2010.08.011

13. Matejka, V., lastimil, Fu.Z., Kukutschová, J., Qi, S., Jiang, S., Zhang, X. Jute Fibers and Powderized Hazelnut Shells as Natural Fillers in Non-Asbestos Organic NonMetallic Friction Composites Materials \& Design 51 2013: pp. $847-853$. https://doi.org/10.1016/j.matdes.2013.04.079

14. Shin, M.W., Cho, K.H., Lee, W.K., Jang, H. Tribological Characteristics of Binder Resins for Brake Friction Materials at Elevated Temperatures Tribology Letters 38 (2) 2010: pp. $161-168$. https://doi.org/10.1007/s11249-010-9586-4

15. Aranganathan, N., Mahale, V., Bijwe, J. Effects of Aramid Fiber Concentration on The Friction and Wear Characteristics of Non-Asbestos Organic Friction Composites Using Standardized Braking Tests Wear 354-355 2016: pp. 69-77. https://doi.org/10.1016/j.wear.2016.03.002

16. Gudmand-Høyer, L., Bach, A., Nielsen, G.T., Morgen, P. Tribological Properties of Automotive Disc Brakes with Solid Lubricants Wear 232 (2) 1999: pp. 168-175. https://doi.org/10.1016/S0043-1648(99)00142-8

17. Hee, K.W., Filip, P. Performance of Ceramic Enhanced Phenolic Matrix Brake Lining Materials for Automotive Brake Linings Wear 259 (7) 2005: pp. 1088-1096. https://doi.org/10.1016/j.wear.2005.02.083

18. Bijwe, J., Kumar, M. Optimization of Steel Wool Contents in Non-Asbestos Organic (NAO) Friction Composites for Best Combination of Thermal Conductivity and TriboPerformance Wear 263 (7) 2007: pp. 1243-1248. https://doi.org/10.1016/j.wear.2007.01.125
19. Gurunath, P.V., Bijwe, J. Potential Exploration of Novel Green Resins as Binders for Nao Friction Composites in Severe Operating Conditions Wear 267 (5) 2009: pp. 789-796. https://doi.org/10.1016/j.wear.2009.02.012

20. Österle, W., Prietzel, C., Kloß, H., Dmitriev, A.I. On the Role of Copper in Brake Friction Materials Tribology International 43 (12) 2010: pp. 2317-2326. https://doi.org/10.1016/j.triboint.2010.08.005

21. Kumar, M., Bijwe, J. Non-Asbestos Organic (NAO) Friction Composites: Role of Copper; Its Shape and Amount Wear 270 (3) 2011: pp. 269-280. https://doi.org/10.1016/j.wear.2010.10.068

22. Seong, J.K., Jae, Y.L., Jai, M.H., Yoon, C.K., Hyun, D.P., Sang, H.S., Jung, J.L., Jae, H.C., Joong, H.J., Ho, J. The Role of Copper on the Friction and Wear Performance of Automotive Brake Friction Materials SAE International Journal of Materials and Manufacturing 5(1) 2012: pp. $9-18$ https: //doi.org/ 10.4271/2011-01-2367

23. Lee, P.W., Filip, P. Friction and Wear of Cu-Free and SbFree Environmental Friendly Automotive Brake Materials Wear $302(1-2)$ 2013: pp. $1404-1413$. https://doi.org/10.1016/j.wear.2012.12.046

24. Aranganathan, N., Bijwe, J. Development of Copper-Free Eco-Friendly Brake-Friction Material Using Novel Ingredients Wear 352-353 2016: pp. 79-91. https://doi.org/10.1016/j.wear.2016.01.023

25. Yun, R., Filip, P., Lu, Y. Performance and Evaluation of Eco-Friendly Brake Friction Materials Tribology International 43 (11) 2010: pp. 2010-2019. https://doi.org/10.1016/j.triboint.2010.05.001

26. Ilanko, A.K., Vijayaraghavan, S. Wear Behavior of Asbestos-Free Eco-Friendly Composites for Automobile Brake Materials Friction 4 (2) 2016: pp. 144-152. https://doi.org/10.1007/s4054

27. Idris, U.D., Aigbodion, V.S., Abubakar, I.J. Eco-Friendly Asbestos Free Brake-Pad: Using Banana Peels Journal of King Saud University - Engineering Sciences 27 (2) 2015: pp. $185-192$. https://doi.org/10.1016/j.jksues.2013.06.006

28. Mittal, M., Chaudhary, R. Biodegradability and Mechanical Properties of Pineapple Leaf/Coir Fiber Reinforced Hybrid Epoxy Composites Materials Research Express 6 2019: pp. 045301. https://doi.org/10.1088/2053-1591/aaf8d6

29. Sandeep, K., Vinay, K.P., $\quad$ Mer, K.K.S., $\quad$ Fekete, G, Brijesh, G., Singh, T. Influence of Woven Bastleaf Hybrid Fiber on the Physico-Mechanical and Sliding Wear Performance of Epoxy Based Polymer Composites Materials Research Express 5 2018: pp. 105705. https://doi.org/10.1088/2053-1591/aadbe6

30. Prabu, V.A., Kumaran, S.T., Uthayakumar, M. Performance Evaluation of Abrasive Water Jet Machining on Banana Fiber Reinforced Polyester Composite Journal of Natural Fibers 14 (3) 2017: pp. 450-457. https://doi.org/10.1080/15440478.2016.1212768

31. Singh, T., Gangil, B., Patnaik, A., Kumar, S., Rishiraj, A., Fekete, G. Physico-Mechanical, Thermal and Dynamic Mechanical Behaviour of Natural-Synthetic Fiber Reinforced Vinylester Based Homogenous and Functionally Graded Composites Materials Research Express 6 2019: pp. 025704. https://doi.org/10.1088/2053-1591/aaee30 
32. Vimal, R., Subramanian, K.H.H., Aswin, C., Logeswaran, V., Ramesh, M. Comparisonal Study of Succinylation and Phthalicylation of Jute Fibres: Study of Mechanical Properties of Modified Fibre Reinforced Epoxy Composites Materials Today: Proceedings 2015: pp. $2918-2927$. https://doi.org/10.1016/j.matpr.2015.07.254

33. Ma, Y.H., Wu, S.Y., Zhuang, J., Jin, T., Yang, X., Hong, Y.Q. The Evaluation of Physio-Mechanical and Tribological Characterization of Friction Composites Reinforced by Waste Corn Stalk Materials 11 (6) 2018: pp. $1-14$. https://doi.org/10.3390/ma11060901

34. Ma, Y.H., Liu, Y.C., Menon, C, Tong, J. Evaluation of Wear Resistance of Friction Materials Prepared by Granulation ACS Applied Materials \& Interfaces 7 (41) 2015: pp. 22814-22820. https://doi.org/10.1021/acsami.5b04654

35. Ho, S.C., Chern Lin, J.H., Ju, C.P. Effect of Carbonization on Mechanical and Tribological Behavior of a CopperPhenolic-Based Friction Material Carbon 43 (3) 2005: pp. 491-502.

https://doi.org/10.1016/j.carbon.2004.09.028

(c) Wang et al. 2021 Open Access This article is distributed under the terms of the Creative Commons Attribution 4.0 International License (http://creativecommons.org/licenses/by/4.0/), which permits unrestricted use, distribution, and reproduction in any medium, provided you give appropriate credit to the original author(s) and the source, provide a link to the Creative Commons license, and indicate if changes were made. 